\title{
To Study the Adequacy of Surgical Muscle Relaxation in Paediatric Patients Scheduled for Elective Groin Surgeries Under General Anesthesia using Sevoflurane without using Neuro- muscular Blocking Agents
}

\author{
Muhammad Ahmad Khan, ${ }^{1}$ Motsim Sheraz, ${ }^{2}$ Sayed Sajjad Raza Kazmi ${ }^{3}$
}

\begin{abstract}
Introduction: In Anesthesia practice neuromuscular blocking agents (muscle relaxants) are used for intobation and surgical muscle relaxation. The use of modern inhalational anesthetics like sevoflurane is commonly practiced in paediatric anesthesia for induction and endotracheal intubation. LMA is alternative to endotracheal intubation. It is commonly used supraglotic device for the elective surgical procedures in adults and paediatric population. We conducted this study to see whether sevoflurane produces enough surgical muscle relaxation so that the use of neuromuscular blocking agents can be avoided.
\end{abstract}

Patients and Methods: 84 paediatric patients of King Khalid Hospital (KSA) from April 2013 to February 2014 posted for elective surgical procedure were included in this observational study regarding the adequacy of surgical muscle relaxation. Induction of anesthesia

Conflict of Interest: No

Funding Source: No

Khan M.A.

Anesthesiology, King Khalid Hospital, Hail Saudi Arabia

Sheraz M. ${ }^{2}$

King Khalid Hospital, Rayadh, KSA

Kazmi S.S.R. ${ }^{3}$

Jinnah Hospital, Lahore was done with propofol $2 \mathrm{mg} / \mathrm{kg}$ and Fentanyl $2 \mathrm{mcg} /$ $\mathrm{kg}$. Airway was maintained with LMA. Anesthesia was maintained by sevoflurane in oxygen and air. Blood pressure and Heart rate was kept with $20 \%$ of baseline reading. Adequacy of surgical muscle relaxation was asked by the surgeon during surgery and was graded as good, fair or poor.

Results: Mean age of the patients was 2.4 year. There were 76 male and 8 female patients. 47 patients were operated for inguinal herniotomy, 32 for orchedopexy and 5 for umbilical herniotomy. Surgical muscle relaxation was good in all of the patients and none of them required use of muscle relaxants. Recovery of all patients was smooth.

Discussion: Adequate surgical muscle relaxation is important to facilitate surgery. In paediatric population sevoflurane produces enough muscle relaxation for intubation and surgical muscle relaxation. Monitoring of muscle relaxation can be clinical as well as through muscle twitches.

Conclusion: Our study showed that in paediatric population the elective surgical procedures of groin region can be done without using muscle relaxants.

Keywords: Paediatric anesthesia, LMA, neuromuscular blocking agents, surgical muscle relaxation.

\section{Introduction}

Muscle relaxants were introduced in anesthesia practice to facilitate the anesthetist for endotracheal intubations and for surgeons through operative site muscle 
relaxation. ${ }^{1}$ Muscle relaxants prevent patient's movements during surgery. Their use avoid overdose of anesthetic drugs that is particularly risky in sick patients and commonly results in delayed recovery.

Use of LMA in anesthesia has revolutionized the practice of anesthesia for elective ambulatory and nonambulatory surgeries. Use of LMA has replaced the need of intubation. ${ }^{2}$ Its use is safe and secure ${ }^{3}$. It can be used in adult and paediatric patients. Its use is comparable with face mask anesthesia for short procedures. ${ }^{4}$

Sevoflurane is commonly used inhalational agent in modern paediatric anesthesia practice. It is safe and effective for the inhalational induction and maintenance of anesthesia. ${ }^{5}$ Sevoflurane produces enough muscle relaxation that is required for paediatric intubation. ${ }^{6}$ It produces rapid awakening and early recovery from anesthesia.

So we conducted this study to find out whether sevoflurane alone produces enough surgical muscle relaxation or not?

\section{Patients and Methods}

We conducted this study after getting institutional permission and patients consent from the parents or guardians. This observational study was conducted in King Khalid Hospital (KSA) from April 2013 to February 2014.

\section{Inclusion Criteria}

1. ASA 1 and 2 paediatric patients coming for elective groin surgeries.

2. All patients undergoing anesthesia by using LMA.

\section{Exclusion Criteria}

1. Patients having ASA status more than 2 .

2. Patients coming for emergency surgeries.

3. Surgeries other than groin region.

4. Patients requiring endotracheal intubations.

5. Patients requiring muscle relaxants.
Base line reading of the blood pressure and heart rate was noted. Induction of anesthesia was done by using propofol $2 \mathrm{mg} / \mathrm{kg}$ and Fentanyl $2 \mathrm{mcg} / \mathrm{kg}$. Maintenance of anesthesia was by using sevoflurane in oxygen and air. LMA was inserted to maintain the airway. Blood pressure and heart rate were kept within $20 \%$ of the baseline reading by titrating sevoflurane and intravenous fluids.

Primary variable was adequacy of surgical muscle relaxation. It was asked from surgeons during the procedures as follow;

Good: Adequate surgical muscle relaxation.

Fair: Less adequate surgical muscle relaxation but no need of muscle relaxant.

Poor: Inadequate surgical muscle relaxation requiring muscle relaxant.

Other variable measured was recovery of the patients. It was noted as smooth or delay.

All the patients were shifted to the recovery room at the end of anesthesia and discharged today surgery unit or ward upon satisfactory recovery.

All the data (age, sex, type of surgery, adequacy of muscle relaxation and recovery status) was analyzed by using SPSS 16 to find out the outcomes. Numerical variables are represented in terms of mean and standard deviation. Qualitative variables are represented as frequencies and percentages.

\section{Results}

Mean age of the patients was 2.4 year. There were 76 male and 8 female patients. 47 patients were operated for inguinal herniotomy, 32 for orchedopexy and 5 for umbilical herniotomy. Surgical relaxation was good in all of the patients and none of them required muscle relaxant. Recovery of all the patients was smooth.

Age of the Patients

\begin{tabular}{|c|c|c|}
\hline \multicolumn{3}{|l|}{ Age } \\
\hline Mean & $\mathrm{N}$ & Std. Deviation \\
\hline 2.401 & 84 & 2.1788 \\
\hline
\end{tabular}




\section{Gender of the Patients}

\begin{tabular}{|c|l|c|c|c|c|}
\hline \multicolumn{2}{|l|}{ Sex } & Frequency & Percent & Valid Percent & Cumulative Percent \\
\hline \multirow{3}{*}{ Valid } & Male & 76 & 90.5 & 90.5 & 90.5 \\
\cline { 2 - 6 } & Female & 8 & 9.5 & 9.5 & 100.0 \\
\cline { 2 - 6 } & Total & 84 & 100.0 & 100.0 & \\
\hline
\end{tabular}

\section{Types of the Surgical Procedures}

\begin{tabular}{|l|l|c|c|c|c|}
\hline \multicolumn{2}{|l|}{ Surgeries } & Frequency & Percent & Valid Percent & Cumulative Percent \\
\hline \multirow{4}{*}{ Valid } & Inguinal Hernia & 47 & 56.0 & 56.0 & 56.0 \\
\cline { 2 - 6 } & Orchedopexy & 32 & 38.1 & 38.1 & 94.0 \\
\cline { 2 - 6 } & Umblical hernia & 5 & 6.0 & 6.0 & 100.0 \\
\cline { 2 - 6 } & Total & 84 & 100.0 & 100.0 & \\
\hline
\end{tabular}

\section{Adequacy of Surgical Relaxation}

\begin{tabular}{|c|c|c|c|c|c|}
\hline \multicolumn{2}{|l|}{ Surgical Muscle Relaxation } \\
\hline \multicolumn{2}{|c|}{} & Frequency & Percent & Valid Percent & Cumulative Percent \\
\hline Valid & Good & 84 & 100.0 & 100.0 & 100.0 \\
\hline
\end{tabular}

\section{Recovery Status of the Patients}

\begin{tabular}{|c|c|c|c|c|c|}
\hline \multicolumn{6}{|l|}{ Recovery Status } \\
\hline \multicolumn{2}{|l|}{} & Frequency & Percent & Valid Percent & Cumulative Percent \\
\hline Valid & Normal & 84 & 100.0 & 100.0 & 100.0 \\
\hline
\end{tabular}

\section{Discussion}

Our study showed that in paediatric groin surgeries, sevoflurane produced enough surgical muscle relaxation and there was no need of additional muscle relaxants.

Muscle relaxants were introduced in anesthesia practice in $1942 .^{7}$ Alan Stead summarized the main advantages of muscle relaxants in paediatric anaesthesia as follows ${ }^{8}$ :

1. They provide a means of effecting (tracheal intobation) and maintaining control of respiration throughout the operation.
2. The patient is completely relaxed and the work of the surgeon is facilitated.

3. The quantity of toxic anaesthetic agents is greatly reduced.

Over dose of muscle relaxants results in delayed recovery and residual neuromuscular blockade resulting in deleterious after effects. Patient has adequate surgical muscle relaxation or not, is variable from surgeon to surgeon and between surgeon and anesthetist. ${ }^{9}$ Muscle relaxation is monitored clinically by surgeons from tense muscles or by anesthetist from patient's breathing activity. It can be monitored by using gadgets with facial or thumb muscle twitches. 
New computer based automatic methods uses this muscle twitches and automatically deliver the required dose of muscle relaxants. ${ }^{10}$

Depth of muscle relaxation required for surgical procedures is comparable with laryngeal muscle relaxation required for endotracheal intubation. Sevoflurane is most common anesthetic agent used for intobations without muscle relaxants and intubations without muscle relaxants is preferred by $>$ one third paediatric anaesthesiologists. ${ }^{11}$ Awad $\mathrm{MT}^{12}$ found that sevoflurane with propofol produces rapid induction. Another studies depicted that propofol $2 \mathrm{mg} / \mathrm{kg}$ was better than $1 \mathrm{mg} / \mathrm{kg}$ with sevoflurane for excellent intu-bation condition. ${ }^{13}$ Blair $\mathrm{JM}^{14}$ showed that sevoflurane is better than propofol and suxamethonium in children intubations. Sevoflurane is very popular in paediatric anesthesia because of its favorable properties. It produces satisfactory induction and intubation condition. It can be used for ambulatory and non-ambulatory paediatric surgeries. ${ }^{15}$ Gas induction has been safely used even in pyloromyotomy. ${ }^{16}$ Aqil $\mathrm{M}^{17}$ found that sevoflurane with Fentanyl was supportive for intubation in adults. Shah $\mathrm{TH}^{18}$ also found it possible to intubate children without neuromuscular block.

Rapid emergence properties of sevoflurane are comparable with desflurane. ${ }^{19}$ But the problem of post anesthesia excitement is very common with sevoflurane in paediatric patients. ${ }^{20}$ Also there is risk of nephrotoxicity with sevoflurane.

So if we have the modern volatile anaesthetic agents like sevoflurane then in paediatric population endotracheal intubation and surgical muscle relaxation can be safely achieved from it.

\section{Conclusion}

Our study concluded that in paediatric population the elective surgical procedures of groin region can be safely preceded alone with sevoflurane without using additional muscle relaxants.

\section{References}

1. Griffiths HR, Johnson GE. The use of curare in general anaesthesia. Anesthesiology, 1942; 3: 418-20.

2. Efrat R, Kadari A, Katz S. The laryngeal mask airway in pediatric anesthesia: experience with 120 patients undergoing elective groin surgery. J Pediatr Surg. 1994 Feb; 29 (2): 206-08.

3. Frediani M, Blanchini G, Capanna M, Casini L, Costa
M, Uggeri S, Meini M, Pacini P. The laryngeal mask in pediatric anesthesia. Minerva Anestesiol. 1996 Mar; 62 (3): 65-71.

4. Watcha MF, Garner FT, White PF, Lusk R. Laryngeal mask airway vs. face mask and Guedel airway during pediatric myringotomy. Arch Otolaryngol Head Neck Surg. 1994 Aug; 120 (8): 877-80.

5. Sarner JB, Levine M, Davis PJ, Lerman J, Cook DR, Motoyama EK. Clinical characteristics of sevoflurane in children. A comparison with halothane. Anesthesiology, 1995 Jan; 82 (1): 38-46.

6. Simon L, Boucebci KJ, Orliaguet G, Aubineau JV, Devys JM, Dubousset AM. A survey of practice of tracheal intubation without muscle relaxant in paediatric patients. Paediatr Anaesth. 2002 Jan; 12 (1): 36-42.

7. Foldes F. The final steps leading to anaesthetic use of muscle relaxants. In: Fukushima K, Ochiai R, eds. Muscle Relaxants Tokyo: Springer, 1995: 8-12.

8. Stead AL. The response of the newborn infant to muscle relaxants. Br J Anaesth. 1955; 27: 124-30.

9. Martini CH1, Boon M, Bevers RF, Aarts LP, Dahan A. Evaluation of surgical conditions during laparoscopic surgery in patients with moderate vs. deep neuromuscular block. Br J Anaesth. 2014 Mar; 112 (3): 498-505.

10. Bradlow HS, Uys PC, Rametti LB. On-line control of atracurium induced muscle relaxation. J Biomed Eng. 1986 Jan; 8 (1): 72-75.

11. Politis GD, Tobin JR, Morell RC, James RL, Cantwell MF. Tracheal intubation of healthy pediatric patients without muscle relaxant: a survey of technique utilization and perceptions of safety. Anesth Analg. 1999 Apr; 88 (4): 737-41.

12. Aouad MT, Yazbeck - Karam VG, Mallat CE, Esso JJ, Siddik - Sayyid SM, Kaddoum RN. The effect of adjuvant drugs on the quality of tracheal intubation without muscle relaxants in children: a systematic review of randomized trials. Paediatr Anaesth. 2012 Jul; 22 (7): 616-26.

13. Siddik - Sayyid SM, Taha SK, Aouad MT, Abdallah FW, Al Alami AA, Kanazi GE. Propofol $2 \mathrm{mg} / \mathrm{kg}$ is superior to propofol $1 \mathrm{mg} / \mathrm{kg}$ for tracheal intubation in children during sevoflurane induction. Acta Anaesthesiol Scand. 2011 May; 55 (5): 535-38.

14. Blair JM, Hill DA, Bali IM, Fee JP. Tracheal intubating conditions after induction with sevoflurane $8 \%$ in children. A comparison with two intravenous techniques. Anaesthesia, 2000 Aug; 55 (8): 774-78.

15. Goa KL, Noble S, Spencer CM. Sevoflurane in paediatric anaesthesia: a review. Paediatr Drugs, 1999 Apr Jun; 1 (2): 127-53.

16. Scrimgeour GE, Leather NW, Perry RS, Pappachan JV, Baldock AJ. Gas induction for pyloromyotomy. Paediatr Anaesth. 2015 Feb 23.

17. Aqil M, Haq A, Rasheed A, Altaf R. Effect of two different doses of fentanyl on intubating conditions with sevoflurane inhalation without neuromuscular blocking 
agents in adults. Anaesth Pain and Intensive Care, 2009 Dec; 13 (2): 52-56.

18. Shah TH. Tracheal Intubation without neuromuscular block in children. JPMI. 2004; 18 (1): 117-23.

19. Ghoneim AA, Azer MS, Ghobrial HZ, El Beltagy MA. Awakening properties of isoflurane, sevoflurane, and desflurane in pediatric patients after craniotomy for supratentorial tumours. J Neurosurg Anesthesiol. 2015 Jan; 27 (1): 1-6.

20. Kobylarz K, Kołaczyk D, Stańczyk M. Sevofluran in pediatric practice - personal experience. Folia Med Cracov. 2001; 42 (4): 211-16. 